\title{
Mitigating adverse customer behaviour for product-service system provision: An agency theory perspective
}

\author{
Wiebke Reim $^{\mathrm{a}, *}$, David Sjödin ${ }^{\mathrm{a}}$, Vinit Parida ${ }^{\mathrm{a}, \mathrm{b}}$ \\ a Entrepreneurship and Innovation, Luleå University of Technology, SE-97187, Luleå, Sweden \\ ${ }^{\mathrm{b}}$ Department of Management, University of Vaasa, FI-65200 Vaasa, Finland
}

\section{A R T I C L E I N F O}

\section{Keywords:}

Product-service systems (PSS)

Agency theory

Trust

Adverse behaviour

Agency mechanisms

Servitization

\begin{abstract}
A B S T R A C T
Offering product-service systems (PSS) arguably results in economic, environmental and social benefits but also entails significant challenges related to relational dynamics between the provider and the customer. Although prior studies suggest that adverse customer behaviour during PSS provision is likely, they provide a limited theoretical understanding of the conceptualization of such relational problems and, more importantly, offer few possible ways to address these problems. By applying the lens of agency theory, this study examines PSS provider-customer relational problems and solutions. Therefore, the purpose of this study is to identify agency problems and propose mechanisms to mitigate adverse customer behaviour in PSS provision. Based on a multiple case study approach involving two manufacturing companies, several results are presented. First, we identify and describe two underlying reasons for adverse customer behaviour. These reasons are associated with goal differentiation and monitoring challenges. Second, different agency mechanisms (i.e. sharing, monitoring and trust) are presented as approaches to mitigate the likelihood of adverse customer behaviour. The matching of agency problems with agency mechanisms to mitigate these problems lays the groundwork for developing a framework for agency situation evaluation during the formation and ongoing phases of the PSS agreement. In addition, the choice of agency mechanism is found to be correlated with the maturity and type of customer relationship and can change over time as new customers become known and then become loyal. The proposed framework has major theoretical implications for the PSS literature as well as managerial implications for large manufacturing companies engaged in PSS provision.
\end{abstract}

\section{Introduction}

Manufacturing companies are increasingly focusing on service-led growth to gain new revenue streams and achieve sustainable competitive advantages. In this regard, servitization by offering product-service systems (PSS) is proposed as an attractive solution for manufacturing companies to achieve economic, environmental and social benefits (Adrodegari, Saccani, Kowalkowski, \& Vilo, 2017; Vezzoli, Ceschin, Diehl, \& Kohtala, 2015). More specifically, through the integration of provider and customer operations, efficiency is increased because each party focuses on its core competencies, and operations are optimised. Thus, PSS has great potential to affect the triple bottom line. For example, prolonged product lifetimes and increased resource utilisation are part of the sustainability achievements that can be achieved through successful PSS implementation (Kuijken, Gemser, \& Wijnberg, 2017; Roy, 2000; Tukker, 2004, 2013).

An under-researched issue within the PSS literature relates to how PSS offerings significantly change the relational dynamics between providers and customers (Schuh, Klotzbach, \& Gaus, 2008; Sundin, Öhrwall Rönnbäck, \& Sakao, 2010). Increased service content inherently leads to closer and more repetitive interactions with customers (Kowalkowski, 2010), whilst responsibility for product performance moves from the customer to the provider for more advanced PSS (Erkoyuncu, Durugbo, \& Roy, 2013). Thus, the logic of PSS offerings raises the likelihood of unintended and unpredictable customer behaviour that affects the provider's operations, and the risk of adverse or opportunistic customer behaviour increases (Ng, Ding, \& Yip, 2013; Sakao, Rönnbäck, \& Sandström, 2013). This study shows that the inability to predict and mitigate adverse customer behaviour represents a major barrier to explaining why numerous manufacturing companies fail to realise the benefits of PSS (Erkoyuncu et al., 2013). Furthermore, changing customer behaviour might negatively influence economic and sustainable achievements and rebound effects could even lead to situations where more resources are consumed, resulting in greater financial losses (Bartolomeo et al., 2003; Manzini \& Vezzoli, 2003). Although a handful of prior studies have acknowledged the negative

\footnotetext{
* Corresponding author.

E-mail addresses: wiebke.reim@ltu.se (W. Reim), david.sjodin@ltu.se (D. Sjödin), vinit.parida@ltu.se (V. Parida).
} 
consequences of customers misusing and/or acting opportunistically to maximise their advantages in PSS (Kuo, 2011; Roy \& Cheruvu, 2009; Sakao et al., 2013), current knowledge is still lacking about how providers can effectively manage adverse customer behaviour.

Agency theory provides a relevant theoretical lens to study unintended or adverse behaviour. This theoretical perspective is particularly applicable in the context of diverse relationship situations where there is potential for asymmetric information and opportunistic behaviour (Eisenhardt, 1989a). PSS offerings represent one such context. An agency relationship exists when a principal delegates a task to an agent who is performing that task (Jensen \& Meckling, 1976). Thus, adverse customer behaviour between provider and customer can be examined by adopting an agency theory perspective to explain how the provider (principal) can manage the risk of adverse behaviour by the customer (agent). More importantly, applying the lens of agency theory to the study of PSS provision can provide novel insights into how the provider can reduce adverse customer behaviour by applying the agency mechanisms that are best suited to PSS provision.

Based on this background, the purpose of this study is to identify potential agency problems and propose mitigating mechanisms to manage adverse customer behaviour in relation to PSS offerings. The present study provides several theoretical contributions to the PSS literature and agency literature. First, this study identifies specific agency problems connected to PSS provision, which tends to entail a higher likelihood of opportunistic customer behaviour and to offset economic and environmental benefits. Second, by suggesting how PSS providers can manage principal-agent relational problems, the present study contributes to the PSS literature, which has long acknowledged relational problems as a core issue preventing the successful implementation of PSS offerings. Third, the development of an agency framework highlights the relevant conditions for the evaluation of the agency situation during the formation phase of the PSS agreement and whilst the agreement is ongoing. Finally, matching selected agency mechanisms to specific sets of agency problems in different situations validates the application of agency theory in a new empirical setting.

\section{Theoretical background}

\subsection{Adverse customer behaviour in PSS}

PSS is defined as an offer model providing an integrated mix of products and services that are together able to fulfil a particular customer demand, based on innovative interactions between the stakeholders of the value production system, where the economic and competitive interest of the providers continuously seeks environmentally and socio-ethically beneficial new solutions (Goedkoop, Halen, Riele, \& Rommens, 1999; Vezzoli et al., 2015). This broad definition indicates that the benefits of PSS enable providers to generate revenue and cost savings as well as environmental benefits for customers from their product-service combinations throughout the life cycle of the PSS.

PSS offerings can vary in their focus, ranging from product- to useand finally to result-oriented PSS (Tukker, 2004). Our study focuses on the more advanced forms of PSS (e.g. pay-per-service, outcome and function), which offer the greatest potential benefits but also require the biggest transformation from standard product-oriented offerings (Reim, Parida, \& Örtqvist, 2015). Therefore, the dynamics of the relationships between providers and customers can vary significantly in the case of add-on product-oriented PSS offers to result-oriented service offers. Based on Sousa and da Silveira (2017) we compare product- and result-oriented PSS offers using several dimensions (Table 1). For example, the predominant contractual relationship changes from transactional and short-term to relational and long-term. Furthermore, the extent to which the provider takes over customer processes is much lower for product-oriented PSS than for result-oriented PSS (Sjödin, Parida, \& Lindström, 2017; Visnjic, Wiengarten, \& Neely, 2016). The service processes and interactions with customers are also much simpler for product-oriented services than for result-oriented services. In addition, most manufacturers have little experience offering such complex services because of the high risk that PSS provider and customer relationships become more ambiguous and less clear (Sjödin, Parida, \& Wincent, 2016). Thus, focusing on result-oriented PSS offers is highly relevant for investigating relational challenges and potential agency problems.

Indeed, offering PSS requires in-depth understanding and management of several unexpected relational challenges. The likelihood of adverse customer behaviour increases significantly because the provider takes over responsibility for product performance from the customer (Caldwell \& Settle, 2011; Erkoyuncu et al., 2013; Ng \& Yip, 2009). This adverse behaviour may be intentional or unintentional. In the marketing literature, this adverse customer behaviour has been discussed in the context of different concepts, such as dysfunctional customer behaviour (Harris \& Reynolds, 2003), disadvantaged customers (Nguyen \& Simkin, 2013) and value co-destruction (Echeverri \& Skålén, 2011; Plé \& Chumpitaz Cáceres, 2010). In contrast, the PSS literature has merely acknowledged such adverse behaviour but this behaviour is poorly understood (Roy \& Cheruvu, 2009). Examples of adverse behaviour include less careful actions when using a product (Kuo, 2011; Tukker, 2004; Ulaga \& Reinartz, 2011), opportunistic behaviour (Ng et al., 2013; Richter, Sadek, \& Steven, 2010) and adverse selection. A specific example is when a customer only buys PSS agreements for machinery that the customer knows is prone to breaking down (Hypko, Tilebein, \& Gleich, 2010). Being unaware and unable to handle these relational challenges can be viewed as a major reason manufacturing companies do not adopt a full-scale PSS strategy and miss out on the huge economic and environmental potential of PSS for both providers and customers.

\subsection{Applying agency theory to PSS relationships}

A major shortcoming of the PSS literature is the lack of theoretical insights into how to conceptualise and understand adverse behaviour between PSS providers and customers. In this regard, agency theory has the potential to offer novel insights to aid our understanding of relational settings where a principal delegates a specific task to an agent (Keow Cheng \& Hon Kam, 2008). Agency problems arise when the principal and the agent have conflicting goals and when it is difficult or expensive to control the agent's behaviour (Eisenhardt, 1989a). The unit of analysis in agency theory tends to be the relationship between the principal and the agent. The metaphor of a contract is used to govern this relationship (Jensen \& Meckling, 1976). Besides describing the classic employer-employee agency relationship (Fama, 1980), agency theory has been effectively applied to designing outsourcing relationships (Logan, 2000) and has been used in various supply chain settings (Ciliberti, De Haan, De Groot, \& Pontrandolfo, 2011; Selviaridis \& Norrman, 2014). Certain studies have applied agency theory to analyse the relationship between service providers (the agent) and their customers (the principal). In those cases, the customer has to cope with asymmetric information and opportunistic behaviour related to the provider's activities (Homburg \& Stebel, 2009; Singh \& Sirdeshmukh, 2000).

Although few studies in the PSS literature have used agency theory logic (Cohen \& Kietzmann, 2014; Hypko et al., 2010), these examples provide informative insights into how agency theory can provide a better understanding of relational problems between provider and customer. Studies have usually focused on adverse provider behaviour and imperfections on the supplier side. Examples of service provider "dark side" behaviour include information misuse, customer confusion, customer lock-in and financial exploitation (Frow, Payne, Wilkinson, \& Young, 2011). For example, Hypko et al. (2010) used agency theory in performance-based contracting to examine the relationship between customers that delegate a task to the manufacturer. Similarly, Cohen 
Table 1

Comparing product- and result-oriented PSS (adapted from Sousa \& da Silveira, 2017).

\begin{tabular}{|c|c|c|}
\hline Dimensions & Product-oriented PSS & Result-oriented PSS \\
\hline Predominant contractual relationship & Transactional, short-term & Relational, long-term \\
\hline $\begin{array}{l}\text { Extent to which provider takes over customer } \\
\text { processes }\end{array}$ & Low & Medium-high \\
\hline Nature of service process & $\begin{array}{l}\text { Quasi-manufacturing, simple, low contact, } \\
\text { standardised }\end{array}$ & Professional, complex, high contact, customised \\
\hline Degree of customer interaction & Low & $\begin{array}{l}\text { High number of customer touchpoints, broad range of personnel } \\
\text { exposed to the customer }\end{array}$ \\
\hline Manufacturers' experience & Long experience and knowledge & Low experience \\
\hline Roles & Clear & Ambiguous \\
\hline Agency problems & Limited & High, bidirectional, different goals, monitoring difficulties \\
\hline
\end{tabular}

and Kietzmann (2014) analysed business models of a sharing economy in which local governments (the principal) delegated the establishment of mobility sharing to a service provider (the agent). In contrast to these studies, the present study seeks to advance our understanding of PSS relationships by depicting the provider as the principal and the customer as the agent. This follows current developments in the PSS literature, in which the customer is seen as the primary source of behavioural uncertainty. For example, the use of the machine or product is the customer's input, which is negatively affected by the customer's adverse behaviour (Roy \& Cheruvu, 2009). Parida, Sjödin, Lenka, and Wincent (2015) described three illustrative cases from diverse industrial settings where customers acted opportunistically when offered result-oriented PSS. One example was an aerospace provider that offered a result-oriented service agreement for its engine turbines. It was discovered that the customer was misusing the turbine for braking purposes. This use meant that the maintenance costs, which were covered by the contract, were significantly higher than in situations without such a contract. This example shows that in PSS agreements, it is particularly important to study the provider as the principal that delegates the task of handling the product to the customer, who takes on the role of agent. Examining the principal-agent relationship from the opposite perspective, as in the present study, has not previously been considered by researchers. This approach offers the potential to significantly contribute to the PSS literature by applying the lens of agency theory to study the problems and mitigation mechanisms of adverse customer behaviour in PSS.

\subsection{Managing agency problems in PSS}

In addition to defining the underlining reasons for agency problems in principal-agent relationships, agency theory also provides insights into how such problems can be mitigated. The traditional model within agency theory calls for two different ways of doing so, either by reviewing the behaviour of the agent (behaviour-oriented contracts) or by reviewing the outcome when the agent has performed its designated task (outcome-oriented contracts) (Eisenhardt, 1989a). Although agency problems (e.g. adverse customer behaviour) have been reported widely in the PSS literature, insights into how to manage such problems remain limited, and the literature currently covers only small, separate aspects of how to manage agency problems (Roy \& Cheruvu, 2009). For result-oriented PSS provision, the application of technical solutions, such as sensors and data handling software that controls the use of the product, is crucial (Isaksson, Larsson, and Rönnbäck, 2009). These technologies are mainly used as tools to create value and support proactive maintenance and to react quickly when problems occur (Opresnik \& Taisch, 2015). But sensors that are built into the product for proactive maintenance can also be used to observe customers' behaviour (Sakao et al., 2013). Disadvantages can be found in the overreliance on technology, and tight control could result in reduced customer loyalty due to the uncomfortable feeling of being watched (Brattström \& Richtnér, 2013). Therefore, all monitoring activities should be specified and agreed upon by contract in advance (Azarenko, Roy, Shehab, \& Tiwari, 2009).

Another way to influence customers' behaviour positively in PSS is by sharing not only profits but also costs in a specified way. The benefits of profit- and risk-sharing are often mentioned in the literature. The objective is to create incentives for both parties (Caldwell \& Settle, 2011; Meier, Roy, \& Seliger, 2010; Richter \& Steven, 2009; Xie, Jiang, Zhao, \& Shao, 2014). The incentive of recovering money if costs are lower than expected and the knowledge that additional costs are also split should prevent adverse customer behaviour because the customer does not benefit from such behaviour (Datta \& Roy, 2013). However, scant attention has been paid to the problems of selling complex and extensive contracts that may scare off customers (Lewis \& Roehrich, 2009). Nevertheless, Datta and Roy (2013) argue that risk-sharing in PSS, which indeed requires significant control and complex contracts, is a way to enhance trust with customers and allows for the possibility of offering PSS to new customers.

Previous research has also acknowledged trust as very powerful for managing relationships between provider and customer (Durugbo, 2013; Homburg \& Stebel, 2009; Logan, 2000; Reim, Rönnberg Sjödin, \& Parida, 2014). Within the PSS literature, researchers commonly agree that a long-term, trusting relationship with the customers is a favourable precondition for offering sustainable PSS (Evans, Partidário, \& Lambert, 2007; Halme, Anttonen, Kusima, Kontoniemi, \& Heino, 2007; Kohtamäki, Partanen, Parida, \& Wincent, 2013; Sundin et al., 2010). Long-term relationships reduce behavioural uncertainty, including the need for monitoring. They also provide the opportunity to charge a risk premium because customers are more aware of the advantages of PSS. However, the provider needs to be aware that building trust is challenging as well as time and resource consuming (Lewis \& Roehrich, 2009). As contracts become more complex and customised, good relationships with the other party are advantageous because contracting depends on an existing trust relationship to motivate the parties to sign a contract (Blomqvist, Hurmelinna, \& Seppänen, 2005; Poppo \& Zenger, 2002).

Overall, the literature has identified various mechanisms for managing agency problems but these mechanisms have not been studied together. In particular, prior literature fails to provide a clear understanding of when (i.e. under which conditions) certain mechanisms are most applicable. Therefore, it is important to consider them in conjunction to mitigate adverse behaviour successfully.

\section{Research methods}

The present study is based on an exploratory multiple case study with two Swedish manufacturing companies (Alpha and Beta) that are actively offering PSS. This research design was chosen because limited knowledge exists regarding the agency mechanisms that offer the best response to adverse customer behaviour in PSS. Information from rich, real-world cases is expected to help identify new aspects and phenomena derived from reality (Eisenhardt, 1989b), including how to 
mitigate adverse behaviour in PSS agreements. To study different agency problems and the mechanisms to mitigate them, two companies that have long-term experience with PSS and that are actively working to develop their PSS offerings were selected. The selection of these cases was motivated by several reasons. First, both companies had reported experiences of facing the challenge of adverse customer behaviour. Second, both companies have adopted a way to monitor the usage of their products and could thus provide insights into the benefits and drawbacks of employing such systems in PSS relationships. Third, they have a wide range of customers that vary globally, especially in terms of relationship duration, which ranges from completely new customers to long-term, trusted partnerships. This also forces the company to apply different contract types to different customers. Finally, good, established contacts with these companies allowed us to go beyond overall firm-level challenges to focus on the PSS agreement between the provider and the customer as the level of analysis. Focusing on agreements allows deeper analysis of contract characteristics (e.g. types of equipment, monitoring capability, risk premium and length of contract) and customer characteristics (e.g. cost sensitivity, length of relationship and cultural difference).

Alpha is an international provider of construction equipment with its head office in Sweden and sales conducted through company-owned as well as independent dealers globally. Currently, the company offers several services that increase the sustainability of their products, such as maintenance contracts, extended warranties, tracking error codes and fuel consumption. The PSS offer that was examined in the present study works as follows: Alpha and its customer agree on a certain availability level, and Alpha is responsible for all activities required to reach that availability level.

Beta manufactures press-hardened automobile parts for the global market. The unit of interest in this case is the tooling department located in Sweden, which internally supplies to press-hardening factories across the globe. Services currently offered include maintenance training, advanced monitoring, simulations and process optimisation. To improve its product-service offer portfolio, Beta is currently developing a PSS that increases the sustainability of its offers by making the use of its tools easier and more reliable for customers.

The research approach for the present study was qualitative and was based on semi-structured and open-ended interviews. In total, 14 respondents from Alpha and 12 respondents from Beta were interviewed. The selection of informants was based on the following criteria: First, selected respondents had to be actively involved in the current service provision and development of their companies. Second, the selected respondents had to belong to various levels and units within the company structure and had to occupy a wide range of positions. For example, several of the interviewees work as product managers for particular services or are involved in the processes of developing and commercialising new PSS offers to global markets. Table 2 provides an overview of the case companies and the respondents' position in each company. Because of the exploratory nature of the interviews, the interview guide was developed based on themes from the existing literature on PSS, agency theory and trust, which were explored in more depth during the interview. Departures from the specific questions in the interview guide were often made to explore particularly interesting themes or illustrative cases uncovered during the interviews. The companies also shared some documents before the interviews that were used to accelerate the process of understanding each company's operations.

The interviews started with a short introduction about the specific focus of the study. The respondents were then asked to explain what they are working on and describe the particular PSS offers they are linked to. This was followed by questions about which general risks they associate with PSS provision. Besides some technical and organizational factors, most respondents cited at least one example of a behaviour risk and possible ways to mitigate these risks. Starting with open-ended questions enabled the respondents to answer without introducing bias by asking about specific adverse behaviour or mechanisms for mitigation. During the course of the interview, the respondents were asked more detailed and probing questions on the different kinds of adverse behaviour and agency mechanisms that can be used to manage customer-provider relationships. Follow-up questions also solicited data on relationships with customers and on the dimensions where differences arose. Furthermore, questions about the use of monitoring equipment were asked as well as questions about the factors that influence the choice of trust or control mechanisms. The face-to-face interviews lasted between 60 and $90 \mathrm{~min}$, and all interviews were recorded and transcribed. The transcribed interviews and notes formed the foundation of the analysis.

The data analysis was based on open coding content analysis, in which headings were written into the transcriptions. These headings related to different agency problems and mitigation mechanisms (Elo \& Kyngäs, 2008). Later, these first-order categories were clustered into theoretically distinct groups (second-order themes). Afterwards, aggregate dimensions were identified (Braun \& Clarke, 2006; Gioia, Corley, \& Hamilton, 2013; Nag, Corley, \& Gioia, 2007). Fig. 1 presents the whole data structure resulting from analysing the interviews. Tables 3 and 4 show additional supporting evidence related to Fig. 1 by presenting representative quotes for each first-order category. We could not find any significant differences in the frequency or importance of the categories, so we evaluated the themes as equally important. Furthermore, several workshops were held with participants from both companies to validate and discuss the research results. The preliminary results of the present study were shared at the validation workshop, and the participants commented and added to the findings.

\section{Empirical findings}

Focusing on offering PSS has evolved as a core component for the case companies' future competitiveness strategy. In this pursuit, they are faced with several issues related to moving beyond simple add-on services to offering more advanced agreements. Both companies highlighted that offering PSS to global markets with diverse customer segments meant that the level of risk was considerably higher because of uncertain and potentially adverse customer behaviour. According to a portfolio manager from Alpha, 'Understanding how our service agreements will be received by global customers is unclear. This creates a lot of speculation and uncertainty within our organisation.' Another respondent from Beta stated the following: 'We have to approach the PSS strategy in steps; otherwise, we can risk too much.' Thus, a lack of understanding regarding how customers might react and behave under PSS agreements represents a major challenge, as does identifying the appropriate mechanism to mitigate adverse customer behaviour.

\subsection{Agency problems in PSS agreements}

To further understand which types of problems are most critical in this setting, we build on agency theory and empirical insight to discuss two conditions that are underlying reasons for agency problems. The first condition specifies that adverse behaviour or conflicts may arise between parties because of different goals. The second condition specifies that if monitoring agents' behaviour is difficult or expensive, agency problems arise because it is impossible to fully know what the agent, in this case the customer, is doing. In the context of the case companies, both conditions are applicable when offering PSS agreements. The customers want to gain as much as possible from the agreement, and it is usually difficult for the case companies to observe how the customer uses the machines or tools. To further understand how the agency problems can be mitigated, it is necessary to identify the underlying dimensions associated with the two conditions in the context of PSS agreements. Further details are provided below on the identified agency problem conditions. Having two parties with different goals essentially creates a situation where each one wants to maximise 
Table 2

Overview of case companies and respondents.

\begin{tabular}{|c|c|c|c|c|}
\hline Company & Industry (PSS offering) & Potential value drivers & $\begin{array}{l}\text { Examples of adverse } \\
\text { customer behaviour }\end{array}$ & Interviews \\
\hline $\begin{array}{l}\text { Alpha }(14,000 \\
\text { employees) }\end{array}$ & $\begin{array}{l}\text { Construction equipment } \\
\text { (availability agreement of } \\
\text { construction equipment } \\
\text { including use optimisation) }\end{array}$ & $\begin{array}{l}\text { Reduced maintenance and } \\
\text { spare parts, reduced fuel } \\
\text { consumption }\end{array}$ & $\begin{array}{l}\text { Overloading machines, } \\
\text { excessively rough driving, } \\
\text { late reporting of problems }\end{array}$ & $\begin{array}{l}\text { 1. Global Product Manager Customer Support Agreements } \\
\text { 2. Global Product Manager Extended Coverage } \\
\text { 3. Project Leader } \\
\text { 4. Product Manager Telematics } \\
\text { 5. Product Manager Remote Control } \\
\text { 6. Portfolio Manager } \\
\text { 7. Global Product Owner Remote Control } \\
\text { 8. Global Pricing Manager } \\
\text { 9. Global Service Solutions } \\
\text { 10. Manager Product Planning } \\
\text { 11. Product Manager EMEA } \\
\text { 12. Soft Product Planning } \\
\text { 13. General Manager Aftersales } \\
\text { 14. Director Global Service Solutions }\end{array}$ \\
\hline $\begin{array}{l}\text { Beta (500 } \\
\quad \text { employees) }\end{array}$ & $\begin{array}{l}\text { Manufacturer of press tools } \\
\text { (availability optimisation } \\
\text { services for press tools) }\end{array}$ & $\begin{array}{l}\text { Reduced maintenance and } \\
\text { spare parts, reduced waste, } \\
\text { reduce energy consumption }\end{array}$ & $\begin{array}{l}\text { Abuse of tools, overuse, } \\
\text { incorrect reporting }\end{array}$ & $\begin{array}{l}\text { 1. Tool Design/Development Manager } \\
\text { 2. Tool Project Leader } \\
\text { 3. Key Account Manager } \\
\text { 4. Controller Tooling Department } \\
\text { 5. Die Engineer (Customer Organisation) } \\
\text { 6. Project Manager Production } \\
\text { 7. Development Manager } \\
\text { 8. Sales Engineer } \\
\text { 9. Sales Manager } \\
\text { 10. Delivery Specialist } \\
\text { 11. Senior Delivery Specialist } \\
\text { 12. Tool Engineer }\end{array}$ \\
\hline
\end{tabular}

First-order categories

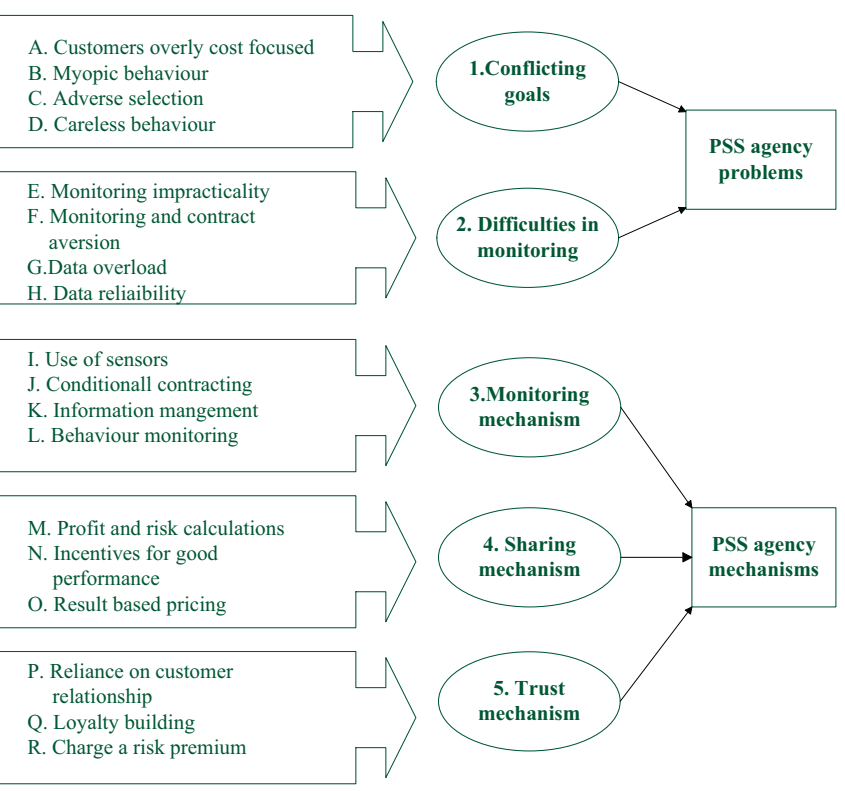

Fig. 1. Data structure and coding process

its own benefits. The provider aims to secure the availability of the customer's products, which has significant positive effects on long-term operations. In contrast, the customer wants to see direct returns for its money, which might lead to myopic behaviour of seeking short-term benefits and prevent a holistic perspective of the balance between loss and gain over time. For example, as a development manager at Beta remarked, 'We are in a very cost-pressured industry, and our customers typically are struggling to keep down costs enough to remain competitive. I think they often focus on short-term cost reductions and forget the long-term consequences of breakdowns. This can be a problem for us.' This self-interest is especially problematic when the customer has a strong cost focus and wants to maximise monetary gains by paying as little as possible for the offer and by getting as much out of the service as possible. Our respondents emphasised that for a provider that has a differentiation strategy and wants to deliver high quality and reliability, goal conflicts often emerge with price-sensitive customers. For example, one global pricing manager at Alpha described how price setting is handled, explaining that certain customers have different price sensitivities: 'Pricing is based on a combination of historical claim costs and also on the market because it is a limit how much you can charge on the market.' As many of the respondents, especially those who work with sales or quoting, explained, offering the service at a low price would hinder the potential to charge a risk premium as a backup for potential higher costs in the future. Another important factor is that certain cultures avoid long-term contractual commitments and thus restrict implementing agreements that are designed and calculated for longer periods.

Furthermore, the existence of different goals between customers and providers becomes visible when customers use information asymmetry to their advantage and only sign agreements for products that they know will cause trouble. A global product manager from Alpha explained this kind of adverse selection: 'There is this adverse selection that the customers know how the machines are used, and if he suspects that this will lead to high costs, then he will sign a contract. But if he thinks it is going to cause fewer problems, then he can take the risk himself. We probably end up with more of the bad agreements in our portfolio.' Accordingly, our respondent highlighted that adverse selection by customers is a key risk with their PSS strategy. The change in responsibility inherent in availability agreements often makes it necessary to expect that the customer will treat the product more carelessly. One respondent from Alpha explained how this could be a key problem when selling availability agreements: 'If you [the customer] are just allowed to load 20 tons but maybe put on 30 tons all the time, the machine will break, and it is a bad business for the provider.' Almost all respondents that work closely with the customers could provide examples of careless behaviour, be it intentional or unintentional.

This shift in customer behaviour is clearly unintended and 
Table 3

Dimensions, themes, categories and quotations for PSS agency problems.
Second-order themes and first-order categories
Supporting quotation

Aggregate dimension: PSS agency problems

1. Different goals

A. Customer overly cost focused

A1. That is a huge risk; that when there is an opportunity to save money, people will grasp it, and it is really hard to find out how and how to predict that

A2. Pricing is based on a combination of historical claim costs and also on the market because it is a limit how much you can charge on the market.

B. Myopic behaviour

B1. Customers don't care about the machines and their behaviour is just ridiculous and they are just abusing the machine and why should they even care because they have an agreement with the dealer which will take care of all the repairs and maintenance.

B2. We are in a very cost-pressured industry, and our customers typically are struggling to keep down costs enough to remain competitive. I think they often focus on short-term cost reductions and forget the long-term consequences of breakdowns. This can be a problem for us.

C. Adverse selection

$\mathrm{C} 1$. The situation is like that they know when the machine is very solid and reliable they tend not to purchase the [service agreement] ... they tend to go for the risky machines, if the machines are in risky environments then they would still go for the [service agreement] because they know that there is a high risk that the machine failed because of the tough environment and so on.

C2. There is this adverse selection that the customers know how the machines are used, and if he suspects that this will lead to high costs, then he will sign a contract. But if he thinks it is going to cause fewer problems then he can take the risk himself. We probably end up with more of the bad agreements in our portfolio.

D. Careless behaviour D1. You can see how many times a machine does shift from the forward to the backwards gear, and if you are still driving with the machine with the full inventory which weights a lot then and if you are then still going forward and shift into backwards, it is very bad for the transmission of the machine, and it has actually heavy damage to a lot of components in the machine. D1. Some things are very evident when it is the operator's fault, and you can always measure those things like overloading, distance or speed.

2. Difficulties in monitoring

E. Monitoring impracticality

F. Monitoring and contract aversion

G. Data overload

H. Data reliability
E1. Also, regarding the environment in which the machines are working, not every error code means the same thing. For example, cooling level is very often an error code, but some machines are driving in a so hard environment going up and down, and then they get an error that your cooling level is low, but then you are on a steep hill.

E2. There might be some environmental conditions that put the machines and sensors under more pressure. When you work in Canada, for example, it is quite rough conditions in many places. Or it can also depend on how close the providers are to the customers; if the customers are very far from the provider, then it is hard to have this monitoring.

F1. Acceptance in the market [for the remote control system] is important for the use of connected products.

F2. I know that especially in Germany people are anxious about integrated sensors and those things related to monitoring.

G1. It is not so easy for the dealers to make sense of all the collected data.

G2. The problem is to cope with the volume of data that we provide. The data is not rocket science.

H1. There are daily issues with [the remote control system] that the data is not reliable and the data is not right compared to the real situation.

H2. We should make [the remote control system] reliable and $100 \%$ available. unwanted by the provider, but the customer's lack of motivation to avoid abusing a product makes this issue problematic. The difference in the parties' goals is strongly influenced by the relationship history and the existence of trust. For example, several respondents described that new customers might focus more on maximising their own, short-term gains from the agreement. As one regional manager at Alpha explains, 'It is really important how brand loyal the customer is because it is much more challenging to have service contracts with non-loyal customers' and 'We recommend that for contracts including repairs, we should know our customers and have trust for each other because otherwise the risk is high that costs will increase significantly.'

Looking at the monitoring side of agency problems, the difficulty and high costs of monitoring can take different forms. First, in some cases, it is just impractical to monitor. For example, some products might be used in remote areas or under special conditions, which makes it impossible to extract data about how they are used and limits the possibility of conducting usage analyses. Such information is critical to guaranteeing availability over time. As a product manager from Alpha explained, 'There might be some environmental conditions that put the machines and sensors under more pressure. When you work in Canada, for example, it is quite rough conditions in many places. Or it can also depend on how close the providers are to the customers; if the customers are very far from the provider, then it is hard to have this monitoring.' The same argument is valid for new or customised products, where the provider lacks experience with the use of the product and is unable to compare the data with existing data. This limits the value of monitoring.

Furthermore, customers that are hesitant to sign extensive contracts or contracts that allow the provider to monitor customer behaviour will increase the risk of agency problems. Many respondents discussed this kind of monitoring and contract aversion. As one product manager at Alpha explained, 'I know that especially in Germany people are anxious about integrated sensors and those things related to monitoring.' These cultural differences are important to consider, and many respondents highlighted similar notions. For example, specific cultures might be more receptive than others to signing contracts that are necessary for legitimate monitoring. As one regional manager at Alpha stated, 'Yes, there are differences, especially when we talk about contracts. Russia, for example, is a booming market for us, and I have heard that they want to have a contract for everything, so to sell a service contract in Russia should be much easier because they are used to sign contracts. In other cultures it is handshakes that count.' Monitoring can also be strategically sensitive, as a delivery manager at Beta emphasised: 'I think some customers would not be happy about us monitoring them, since this would spread knowledge about how they run their operations. This would be a hard sell.' Furthermore, even though the customer has to agree that the machine is equipped with sensors, monitoring is a critical issue that may be a key concern for labour unions. Indeed, it might violate the integrity of the employee because it could be interpreted as observation.

However, scarce data is not the only cause of difficulties in monitoring. Data overload and an inability to use and analyse the existing data in a useful way are also hindrances for providers. It requires a lot of work to be able to use the data from all sensors and other measurements to gather beneficial information and draw conclusions about customer behaviour. The product manager for Alpha's monitoring system was clearly aware of this: 'The problem is to cope with the volume of data that is provided.' This is further complicated by the fact that data 
Table 4

Dimensions, themes, categories and quotations for PSS agency mechanisms.

Second-order themes and first-order categories Supporting quotation

Aggregate dimension: PSS agency mechanisms

3. Monitoring mechanism

A. Use of sensors

I1. We are seeing the machine hours - the machine is close to a service, or high idle time, the machine is maybe not used productively or high fuel consumption. There is a chance for operator training.

I2. It's a precondition for selling uptime to have the machines connected to remote control. Otherwise, we don't know how the machine is doing.

B. Conditional contracting

J1. I think it is too high risk to say 'don't care; we fix it'. We need to agree in advance which conditions apply for this service. If we don't agree with the customer about the agreement terms, the customers can use the machine how hard they want and it is still our fault.

J2. There is actually kind of hard terms and conditions. Nowadays, we say that the agreement is only valid in normal conditions of use, so if there is any evidence of abnormal usage, the agreement can be cancelled.

C. Information management K1. The agreements are written that the customer asks for the collection of the data, and the data can then be used to improve the product and customer's operation.

K2. We are not supposed to control our customers. It is about making them understand that we use remote control to keep their costs down, their fuel consumption down and use the information to optimise their operations.

D. Behavioural monitoring

L1. There are a lot of parameters you can measure to identify bad behaviour, such as speed, error codes and so on.

L2. All dealers have a feeling if something breaks because of the machine's quality or the misuse of the customer.

4. Sharing mechanism

E. Profit and risk calculations

F. Incentives for good performance

G. Result based pricing

5. Trust mechanism

H. Reliance on customer relationship

I. Loyalty building

J. Charge a risk premium
M1. If we have a risk-sharing, we should have a positive and negative risk-sharing.

M2. If we can share costs and profits with the customer, we can win many orders. But, of course, agreeing on how the sharing should be done is not that easy, and we need to prepare ourselves to be comfortable in these calculations.

N1. Combine it with some type of profit and risk-sharing that if they are claiming less than they have paid, then we would reimburse them $50 \%$ or whatever, and when the costs are going over that, they are paying extra.

N2. If the repairs are less than budgeted, there is an agreement with the customer that they get back $50 \%$ of that profit, but this would be more profit-sharing than risk-sharing. But you could have risk-sharing as well and say that if the contract goes worse than the budget, the customer has to take 50 or $40 \%$ of the costs.

O1. If we have risk-sharing, we need to know exactly the outcome of the agreements.

O2. The sharing would be based on certain periods, and in the beginning, the repair costs are low but may become much higher than expected in the end. If you share the money in the beginning, you might lose in the end instead. The more you use something, the more wear-out you have. I think that you should be careful about what you are sharing profits on.

P1. If they have some good trust or some kind of informal bond in between that, they trust each other and they don't sign anything, so some dealers don't want to sign up in a contract because it sounds like harming their trust on their customers. So for certain cases, they just do some kind of verbal agreement.

P2. In some cases, much is built on trust. I trust that you do what we agreed upon.

Q1. In most cases, it is quite easy to know whose fault the breakdown is. But you need to balance the risk of ending up with a bad relationship to the customers. Things can break even when everything was done correctly.

Q2. It should only be the exception to use the data against the customer; I would not recommend it. The company should instead take the hit to prevent damage to the relationship with the customer.

R1. It is somehow mixed between the historical price benchmark and then a cost plus.

R2. If the costs for the agreement are lower than we charged for, we earn extra money. reliability is vital for the use of monitoring insights against customers. One respondent working in developing the monitoring system at Alpha clearly saw that problem: 'We have daily issues with our monitoring system that the data is not reliable and the data is not right compared to the real situation, so we have to map that risk for the data reliability.' All respondents that work with data management expressed concerns about the limitations of the available data. Having the data but not being able to use it to control what the customer is actually doing will not reduce agency problems.

To conclude, we found that agency problems related to adverse customer behaviour are a key risk for the case companies. When the case companies become responsible for repairs and maintenance by making products available, they are exposed to the consequences of customer usage. For example, overloading a truck, driving too fast or shifting the gears inappropriately will wear out critical components, so more repairs will be necessary to secure the availability of the product.

\subsection{Agency mechanisms for managing agency problems in PSS agreements}

All agency problems cannot be mitigated through only one initiative. The empirical findings suggest that agency problems can be handled in various ways. We used these findings to develop three distinctive agency mechanisms that can be used to solve agency problems. Agency theory and the related literature in the field of PSS do not provide a holistic picture of how the agency problems described above can be mitigated. Below, the three mechanisms are described, together with their advantages and disadvantages, which can be used to match the agency mechanisms with the agency problems that they can mitigate.

The first type, the monitoring mechanism, is related to behaviouroriented contracts in agency theory. With this mechanism, agreements clearly define the responsibilities and obligations of each party. For example, integrated sensors are essential when offering a business model that guarantees product availability because they enable the provider to monitor the product and react immediately when things go wrong. These integrated sensors can also be used to extract data on customer behaviour. This data can be used to manage how the customer is treating the machine (i.e. in the intended way). This would mitigate abuse and careless behaviour; otherwise, the agreement could be cancelled. As a senior project manager from Beta explained, 'Contracts are important for us to secure that our products would be used as intended.' In particular, this mechanism is easy to integrate in the contract terms, as one respondent explained: 'We say that the PSS contract is only valid in normal conditions of use, so if there is any evidence of abnormal usage, the PSS contract can be cancelled because that was not part of the contract when you signed the contract.' The advantage that the customers' behaviour can be controlled effectively shows that this mechanism is appropriate when dealing with new, unknown customers. However, many respondents found that extensive, tight contracts might scare off potential customers because customers might not feel comfortable with all the regulations with which they have to comply. Furthermore, such extensive contracts can be seen as a reduced service level. In addition, 
Table 5

Overview of the identified agency mechanisms in PSS.

\begin{tabular}{|c|c|c|c|}
\hline Agency mechanism & Advantages & Disadvantages & Which agency problem does it mainly mitigate? \\
\hline Monitoring & $\begin{array}{l}\text { - Control customer behaviour } \\
\text { - Contract can be cancelled when adverse } \\
\text { behaviour occurs }\end{array}$ & $\begin{array}{l}\text { - Monitoring can be seen as observation } \\
\text { - -Tight contracts may scare off customers }\end{array}$ & $\begin{array}{l}\text { - Careless behaviour } \\
\text { - Myopic behaviour }\end{array}$ \\
\hline Sharing & $\begin{array}{l}\text { - Incentives for good behaviour } \\
\text { - Limited risk for provider }\end{array}$ & $\begin{array}{l}\text { - Less payoff for good performance } \\
\text { - Periodical offset might result in an overall } \\
\text { loss } \\
\text { - Requires sharing sensitive data (profits and } \\
\text { costs) } \\
\text { - Tight contracts }\end{array}$ & $\begin{array}{l}\text { - Cost focus } \\
\text { - Adverse selection } \\
\text { - Monitoring impracticality }\end{array}$ \\
\hline Trust & $\begin{array}{l}\text { - No complex contracts } \\
\text { - Fosters loyalty }\end{array}$ & $\begin{array}{l}\text { - Expenses for trust building } \\
\text { - Requires charging a risk premium }\end{array}$ & $\begin{array}{l}\text { - Monitoring impracticality } \\
\text { - Monitoring and contract aversion } \\
\text { - Data overload } \\
\text { - Data reliability }\end{array}$ \\
\hline
\end{tabular}

certain customers belong to cultures that dislike either monitoring or tight contracts with a lot of specifications on what they are supposed to do. For these customers, the monitoring mechanism should not be applied; instead, other mechanisms should be considered.

The second type, the sharing mechanism, is similar to output-oriented contracts because the revenues or profits as well as risks are shared with the agent. In this scenario, the provider keeps track of all its operations and compares it with the price the customer pays for the availability offer. One customer solutions manager at Alpha explained how they had worked with this type of mechanism with some customers: 'If the repairs are less than budgeted, there is an agreement with the customer that they get back 50 percent of that profit, but this would be more profit-sharing than risk-sharing. But you could have risk-sharing as well and say that if the contract goes worse than the budget, the customer has to take 50 or 40 percent of the costs above budget.' Using a mechanism like this is a powerful incentive for the customer to treat the machine well, and both parties work towards the same goal because both are interested in increasing the machine's availability. Because such agreements are very transparent on the provider's costs and profits, a customer that is focused on reducing costs will be attracted to this agreement. A development manager from Beta explained: 'If we can share costs and profits with the customer, we can win many orders. But, of course, agreeing on how the sharing should be done is not that easy, and we need to prepare ourselves to be comfortable in these calculations.' For the provider, these agreements limit their risk of losses. Thus, adverse selection or monitoring impracticality is not as problematic because the provider shares the risks with the customer. This sounds promising, but it has drawbacks as well. As one contract manager at Alpha with significant experience in this area stated: 'The sharing would be based on certain periods, and in the beginning, the repair costs are low but may become much higher than expected in the end. If you share the money in the beginning, you might lose in the end instead. The more you use something, the more wear-out you have. I think that you should be careful about what you are sharing profits on.' Generally, the respondents, in particular product managers, agreed that the sharing mechanism should be avoided when it is possible to use other mechanisms. This is the case because this mechanism limits the possibility to capture the whole potential of the agreement. Indeed, it requires sharing all data about the costs and situations that might occur in which the shared profits early on cannot offset losses in later periods of the agreement. Ideally, sharing-based contracts should be seen more as an 'order winner' when the customer has a cost focus.

Finally, the trust mechanism is the third alternative for reducing adverse behaviour. This mechanism means that no specifications about customer obligations are made, and monitoring data is not used against the customer. Instead, the customer is trusted to behave in the intended way and not change its behaviour because of the agreement. The main reason for using this mechanism is to maintain a good customer relationship. For example, although monitoring data about customer behaviour is available, one of the respondents clearly advised against using this data: 'It should only be the exception to use the data against the customer; I would not recommend it. The company should instead take the hit to prevent damage to the relationship with the customer.' For this mechanism to work, the provider must be able to charge a risk premium for the offer as a backup if the customer still causes extra expenses. Yet the case companies offer high-quality products with their differentiation strategy that consists of satisfied customers with high brand loyalty driven by the product's good performance. It should therefore be possible to include a risk premium in the price. The respondents noted that contracts built on the trust mechanism are most desirable because they indicate a good relationship with customers, and the risk premium offers a good incentive to do excellent work. In some cases, applying the trust mechanism might be necessary because the other mechanisms are not possible. This is the case, for example, when customers are adverse to monitoring or contracts and forming an agreement is only possible if it is based on the trust mechanism. According to one respondent from Alpha, 'If they have some good trust or some kind of informal bond in between that, they trust each other and they don't sign anything because it sounds like harming their trust to the customers. So, for certain cases, they just do some kind of verbal agreement. They say this is what we are going to do, but they don't really sign up.' Nevertheless, the trust mechanism should be avoided when customers are focused mainly on their own short-term benefits and adverse behaviour is suspected. Table 5 summarises the findings from this section, including the insights into which problems can be best solved with which mechanism.

\subsection{Towards a framework for matching agency problems to agency mechanisms}

The empirical insights explain the reasons for agency problems as well as potential mechanisms for mitigating adverse customer behaviour for result-oriented PSS agreements. In this section, these insights are combined to develop a framework for matching agency mechanisms to agency problems. However, matching identified agency problems to agency mechanisms can only be done effectively based on further analysis of certain conditions that are specific to the PSS-agreement context. One respondent from Alpha exemplified this matching logic: 'it is impossible to make a one-size-fits-all agreement with the customers to sell the product, so I think that it is important to make flexible contracts and also flexible operations and adapt to the situation at hand.' The purpose of this framework is to explain relevant conditions for selecting the use of agency mechanisms at the initial formation phase of PSS agreements and during the ongoing phase of PSS agreements. It is important to recognise that PSS agreements have a duration of several years (e.g. 3-5 years), and it is important to make a well-grounded decision about the agreements when signing a contract whilst continuously re-evaluating the agreement as surrounding situations change. Fig. 2 connects the key findings in relation to developing an agency framework for result-oriented PSS provision. 
Agreement formation phase

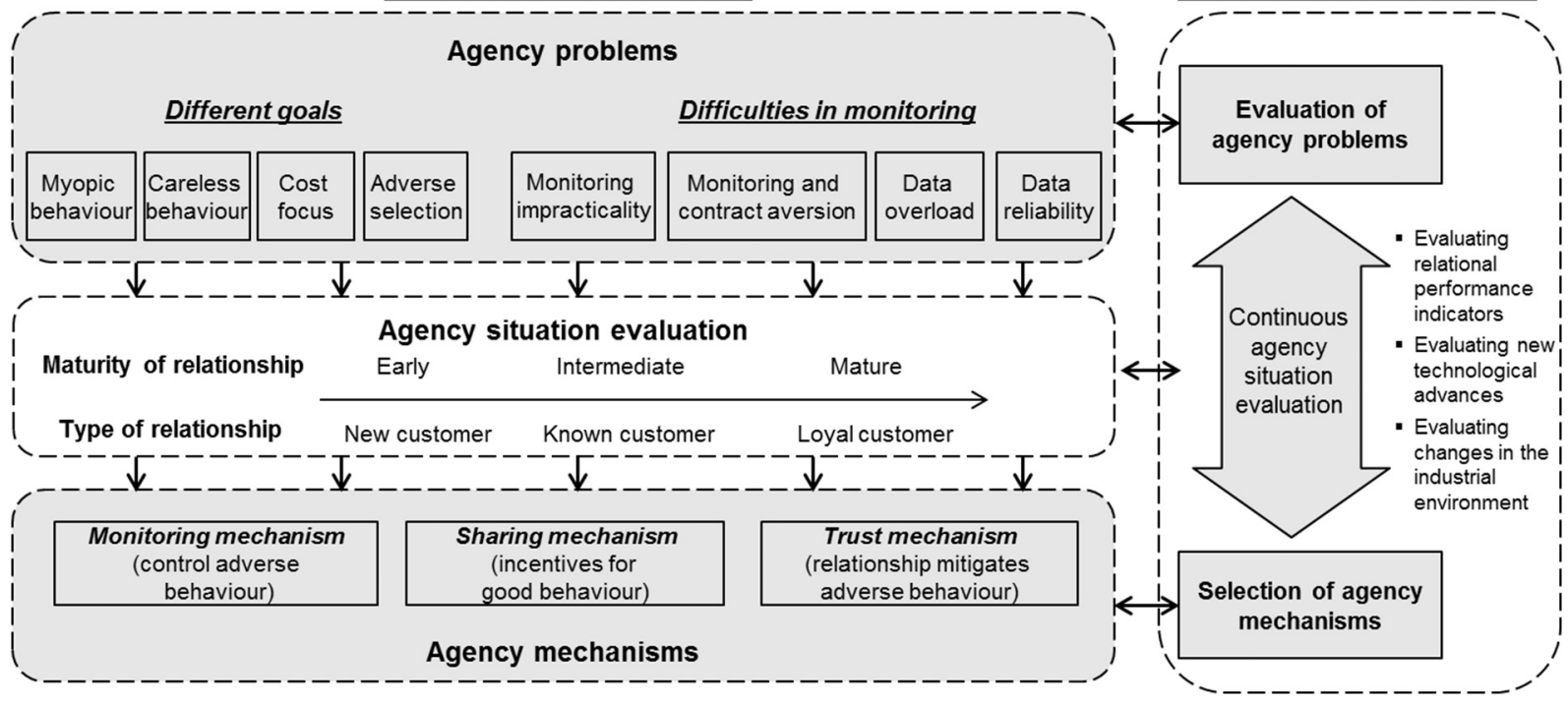

Fig. 2. An agency framework for matching agency problems to agency mechanisms based on evaluating the agency situation over time.

The key arguments inherent to the agreement formation phase of the framework is that matching the diverse characteristics of the agency problems and the choice of agency mechanisms largely depends on the evaluation of the agency situation. The main factors forming the agency situation during the agreement formation phase are maturity and types of relationship between provider and customer. Thus, the choice of an agency mechanism to mitigate adverse behaviour differs over time as the relationship develops, such as early, intermediate and mature. In addition, this dynamic is also closely related to the type of relationship, which, according to the relationship life cycle literature (Mascarenhas \& Koza, 2008), can be divided into three phases: new customer, known customer and loyal customer.

In the formation phase, the provider cannot rely on experience, historical data or existing relations learning, which would be necessary to calculate appropriate risk premiums for trust-based contracts or to develop appropriate sharing agreements. Because the provider lacks a history with the customer, it is impossible to know whether new customers are trustworthy and how they will behave. For example, some customers were noted to have operating environments that wore out machines very quickly compared to industry benchmarks. Thus, predicting wear-out rates with new customers proved very difficult. Being able to monitor behaviour makes experience with the customer much less important. Therefore, the monitoring mechanism is the best-suited mechanism when offering PSS to new customers. Also, inadvertent adverse behaviour might be more common amongst customers that are unfamiliar with the equipment. Even when identifying unintended behaviour, the information can be used to provide training or clarification to mitigate adverse behaviour in the future.

Over time, relationships develop and enter intermediate-level maturity, where historical data becomes available for evaluation. In this situation, known customers may not have to be managed extensively using the monitoring mechanism. Thus, the sharing-based contract mechanism may be more suitable in this maturity stage of the relationship. By creating incentives for good behaviour, the sharing mechanism helps create common goals that reduce the cost focus or adverse selection. In this phase, the provider might not intend to use the monitoring mechanism, but if the provider suspects, for example, careless or myopic behaviour, the monitoring data can still be used to verify suspicions later when facing such agency problems. Nevertheless, the provider should try to incentivise good relationships with the customers so that in the future, the trust mechanism becomes relevant.

When the relationship matures and reaches the stage of long-term loyal customers, the trust-based contract mechanism becomes the most suitable choice. Experience provides enough information to foresee the outcomes of a PSS agreement, and common goals should have been established in the past. The reliability of the equipment is most important for both customer and provider, and it is hoped that both are doing their best to achieve the best outcome of the agreement. The trust mechanism allows for profit margins, increases customer loyalty and requires the least effort in terms of monitoring. However, the evaluation of the agency situation does not always follow a linear development of relationship phases and types. Even though the provider may have a clear preference for the trust mechanism, it might be necessary to analyse past agreements based on indications for adverse behaviour that would be better managed through one of the other agency mechanisms. However, when trust is the optimal mechanism because of factors such as increased customer loyalty, the company should make a continuous effort to build trusting relationships without being unrealistic and taking all the risks.

In addition, evaluation of the agency situation is not a one-time decision. It needs to be continuously re-evaluated throughout the resultoriented PSS agreement period. Agency problems might change during the agreement period, which would affect the choice of preferred agency mechanism. Because a duration of 5-10 years for a PSS agreement is not uncommon, these agreements should include regular meetings between both parties where the outcomes for the agreement are reviewed and adapted, if needed. Our results indicate three general principles for continuous evaluation of the agreement.

First, the parties should focus on evaluating relational performance indicators to see if the predefined targets have been met. Examples of relational performance indicators include meeting the promised output level or cost level. Based on such assessments, the parties can discuss whether, for example, performance is better than expected and the monitoring did not reveal any signs of adverse behaviour so that they can engage in a sharing agreement or move towards the trust mechanism.

Second, evaluating new technical advances is important because it can affect agency problems and thus the choice of appropriate agency mechanism. For example, this could mean that agency problems related to difficulties in monitoring are solved through technical advances, and the monitoring mechanism and more data can be evaluated, or new technology can be integrated into equipment to enable higher productivity.

Finally, the third factor, evaluation of changes in the relational 
environment, is concerned with the analysis of how external factors like economic downturn can affect the choice of agency mechanism. For example, a downturn will make the customer more cost focused. Therefore, the monitoring or sharing mechanisms might be necessary instead. Nevertheless, the findings indicate that providers should work jointly with customers to meet their preferences. By doing so, they will secure the largest economic and environmental potential that the agreements entail.

\section{Discussion}

Providing PSS has major potential to enhance providers' and customers' operations and benefit the environment. However, the altered relationships between the two parties create the potential for adverse behaviour, which needs to be actively mitigated (Hypko et al., 2010; Tukker, 2004; Ulaga \& Reinartz, 2011). Previous studies mainly recognise adverse behaviour on the provider side, leaving room for developing further insights into how to address the behaviour from provider and customer perspectives (Cohen \& Kietzmann, 2014; Frow et al., 2011). The present study contributes to this discussion by identifying agency problems and mechanisms to mitigate problems in the context of result-oriented PSS provision. The findings of the present study are summarised and used to develop a framework that focuses on matching sets of agency problems with appropriate agency mechanisms. Accordingly, the present study offers significant theoretical and practical implications, which are detailed below.

\subsection{Theoretical implications}

The main contribution of the present study is to the PSS literature. Although the literature acknowledges the risk of adverse behaviour (Kuo, 2011; Roy \& Cheruvu, 2009), the analysis is fragmented, and insights into how such relational problems can be solved are lacking. The present study fills this gap by identifying and exemplifying which different principal-agent problems are relevant, from the provider's perspective, in providing PSS agreements. By using the lens of agency theory, the present study focuses on two dimensions of agency problems (i.e. different goals and difficulties in monitoring) (Jensen \& Meckling, 1976), which enables a novel yet structured way of analysing possible sources of adverse behaviour in PSS. The present study illustrates the importance of agency problems relating to different goals in the form of various dimensions such as cost focus, myopic behaviour, adverse selection and careless behaviour in PSS agreements. Similarly, difficulties in monitoring can arise through monitoring impracticality, monitoring and contract aversion, data overload, and problems with data reliability. The literature emphasises that adverse behaviour is an important issue to consider in PSS (Hypko et al., 2010; Kuo, 2011; Ng et al., 2013), but it does so only in a scattered way that fails to present a holistic picture of what causes agency problems.

A second key contribution of the present study is the identification and categorisation of three key agency mechanisms that can mitigate adverse behaviour for result-oriented PSS agreements: monitoring, sharing and trust mechanisms. The traditional approach to solving agency problems can be divided into two key strands within the PSS literature: those concerned with monitoring systems (i.e. comparable to behavioural-based contracts in agency theory) and those concerned with profit- and risk-sharing contracts (i.e. comparable to outcomebased contracts in agency theory). The present study shows that combining the trust mechanism with the classic agency mechanisms of behavioural- and outcome-based contracts significantly improves the understanding of the various mechanisms that can be used to mitigate adverse behaviour. Each of these mechanisms has its benefits and drawbacks, but, as our results show, they are also appropriate to solve certain types of agency problems. For example, the sharing mechanism is advisable when customers have a strong cost focus, whereas the trust mechanism is typically required when dealing with contract- and monitoring-adverse customers. By identifying the contingencies (agency problems) that explain the relevant agency mechanisms to use in PSS, the present study contributes to several current discussions in the PSS literature that call for a more complex relational framework. The results of the present study contribute primarily to a better understanding of the relevance of monitoring (Erkoyuncu, Roy, Shehab, \& Wardle, 2009; Reim, Parida, \& Sjödin, 2016; Sakao et al., 2013), the role of profit- and risk-sharing (Caldwell \& Settle, 2011; Datta \& Roy, 2013), and the importance of trust (Evans et al., 2007; Halme et al., 2007) in specific relational situations.

Third, to match agency problems with agency mechanisms, a framework has been developed that includes the evaluation of agency situations during formation of the PSS agreement and whilst the agreement is ongoing. Deciding which mechanism is most appropriate for a certain agreement with a certain customer is complex and depends heavily on the maturity of the provider-customer relationship as well as on the type of customer. This complexity exists primarily because the agency situation is dynamic and changes as the customer-provider relationship develops. However, these changes need not be linear in all cases as agency problems can also surface even in trusted relationships and might thus lead to a situation where, for example, the monitoring mechanism has to be used. Furthermore, the framework highlights the importance of continuous evaluation of the agency situation. Because of the long-term duration of PSS agreements, agency problems can change over time, which also affects the choice of the most appropriate agency mechanism. Good performance, technical advances or a changing environment might be reasons for adapting the agency mechanism. Even though the development of a relationship over time when providing PSS has been considered together with the importance of trust (Kindström, 2010; Sundin et al., 2010), scarce attention has been devoted to the influence of the customer relationship on the use of mechanisms to manage adverse customer behaviour. Particularly, a holistic view of the total lifetime of PSS agreements has been lacking. This view is crucial because adverse customer behaviour can emerge during all phases of the agreement period. Through continuous evaluation of the agency situation, it is possible to align the goals of the provider-customer relationship at all times.

In addition to contributing to the PSS literature, the present study also has implications for the agency theory literature. In particular, principal-agent problems with the PSS provider as the principal and the customer as the agent are examined. This is a novel approach in the service literature, which generally assumes that the provider may behave opportunistically and may engage in adverse behaviour when providing services (Cohen \& Kietzmann, 2014; Singh \& Sirdeshmukh, 2000). By leveraging the bidirectional, actor-to-actor nature of service supply chains (Ekman, Raggio, \& Thompson, 2016; Sampson, 2000), this new conception of the principal-agent problem adds a new perspective of significant value to the applicability of agency theory in PSS and the operations management literature.

\subsection{Managerial implications}

The study also provides several recommendations for management. The results have major implications for marketing and operational managers who are responsible for selling and delivering PSS to diverse customers. First, the importance of understanding the consequences of adverse behaviour in relation to diverse customers is emphasised. Indeed, failing to consider the effects of adverse customer behaviour can have severe financial consequences for providers of availability contracts. Managers dealing with these issues should thus be aware of the risk of adverse behaviour and should make structured assessments of such risks for each new PSS offering that is directed towards a customer. Mapping the presence of such risks according to the different conditions of agency problems included in our framework could help managers make more structured analyses of their risk levels. Second, the framework serves as a guide for selecting the preferred agency 
mechanism to manage adverse behaviour. Making such selections, however, is not easy. Highlighting the complexity of such decisions provides a structure for managers to consider different aspects related to mitigating adverse behaviour. Third, the results emphasise the importance of making a separate decision for each specific relationship and agreement and of re-evaluating this decision over time. Finally, failure to actively manage adverse behaviour in PSS could create resistance in the company to use potential PSS offers. This would create negative environmental impacts as sustainable PSS agreements significantly contribute to higher resource utilisation.

\subsection{Limitations and further research}

Although the results of the present study clearly contribute to the PSS literature, the study does have certain limitations that should be considered when evaluating the results and that should be addressed in future studies. First, the case companies were actively working to develop their PSS offers to capitalise on their long experience in productservice offerings. Nevertheless, because we studied only two very similar case companies, generalisations are difficult to draw; additional cases would provide further insights that cannot be gained from the present study. Therefore, further empirical studies are needed to validate the present study's findings. Second, this study was based on Swedish manufacturing companies. The results could be different in other cultural or industrial settings. Future research should determine whether these findings hold under other conditions. Third, this study identifies a list of agency problems that need to be mitigated through agency mechanisms. This list may be incomplete, and the problems are neither set in relation to each other nor proffer a weighting to determine the most critical factor. Extending the list and creating this weighting would be beneficial for future sustainable PSS provision. Finally, this study focuses on the agency situation where the provider (principal) wants to mitigate the risk of adverse behaviour by the customer (agent). However, this relationship is bidirectional, and the agency situation might be the other way around. For example, the customer might also have a certain preference for a mechanism to mitigate adverse behaviour by the provider. Future research should therefore study the other way in more detail or combine these two ways to further study co-destruction and thereby enhance our understanding of agency issues in PSS.

\section{References}

Adrodegari, F., Saccani, N., Kowalkowski, C., \& Vilo, J. (2017). PSS business model conceptualization and application. Production Planning and Control, 28(15), 1251-1263.

Azarenko, A., Roy, R., Shehab, E., \& Tiwari, A. (2009). Technical product-service systems: Some implications for the machine tool industry. Journal of Manufacturing Technology Management, 20(5), 700-722.

Bartolomeo, M., dal Maso, D., de Jong, P., Eder, P., Groenewegen, P., Hopkinson, P., Slob, A. (2003). Eco-efficient producer services-What are they, how do they benefit customers and the environment and how likely are they to develop and be extensively utilised? Journal of Cleaner Production, 11(8), 829-837.

Blomqvist, K., Hurmelinna, P., \& Seppänen, R. (2005). Playing the collaboration game right-Balancing trust and contracting. Technovation, 25(5), 497-504.

Brattström, A., \& Richtnér, A. (2013). Good cop-bad cop: Trust, control, and the lure of integration. Journal of Product Innovation Management, 31(3), 584-598.

Braun, V., \& Clarke, V. (2006). Using thematic analysis in psychology. Qualitative Research in Psychology, 3(2), 77-101.

Caldwell, N. D., \& Settle, V. (2011). Incentives and contracting for availability: Procuring complex performance. Complex engineering service systems (pp. 149-162). Berlin: Springer.

Ciliberti, F., De Haan, J., De Groot, G., \& Pontrandolfo, P. (2011). CSR codes and the principal-agent problem in supply chains: Four case studies. Journal of Cleaner Production, 19(8), 885-894.

Cohen, B., \& Kietzmann, J. (2014). Ride on! Mobility business models for the sharing economy. Organization and Environment, 27(3), 279-296.

Datta, P. P., \& Roy, R. (2013). Incentive issues in performance-based outsourcing contracts in the UK defence industry: A simulation study. Production Planning \& Control, 24(4-5), 359-374.

Durugbo, C. (2013). Competitive product-service systems: Lessons from a multicase study. International Journal of Production Research, 51(19), 5671-5682.
Echeverri, P., \& Skålén, P. (2011). Co-creation and co-destruction: A practice-theory based study of interactive value formation. Marketing Theory, 11(3), 351-373.

Eisenhardt, K. M. (1989a). Agency theory: An assessment and review. Academy of Management Review, 14(1), 57-74.

Eisenhardt, K. M. (1989b). Building theories from case study research. Academy of Management Review, 14(4), 532-550.

Ekman, P., Raggio, R. D., \& Thompson, S. M. (2016). Service network value co-creation: Defining the roles of the generic actor. Industrial Marketing Management, 56, 51-62.

Elo, S., \& Kyngäs, H. (2008). The qualitative content analysis process. Journal of Advanced. Nursing, 62(1), 107-115.

Erkoyuncu, J., Roy, R., Shehab, E., \& Wardle, P. (2009). Uncertainty challenges in service cost estimation for product-service systems in the aerospace and defence industries. Proceedings of the 19th CIRP design conference-competitive design. Cranfield University Press.

Erkoyuncu, J. A., Durugbo, C., \& Roy, R. (2013). Identifying uncertainties for industrial service delivery: A systems approach. International Journal of Production Research, 51(21), 6295-6315.

Evans, S., Partidário, P. J., \& Lambert, J. (2007). Industrialization as a key element of sustainable product-service solutions. International Journal of Production Research, 45(18-19), 4225-4246.

Fama, E. F. (1980). Agency problems and the theory of the firm. The Journal of Political Economy, 88(2), 288-307.

Frow, P., Payne, A., Wilkinson, I. F., \& Young, L. (2011). Customer management and CRM: Addressing the dark side. Journal of Services Marketing, 25(2), 79-89.

Gioia, D. A., Corley, K. G., \& Hamilton, A. L. (2013). Seeking qualitative rigor in inductive research notes on the Gioia methodology. Organizational Research Methods, 16(1), 15-31.

Goedkoop, M., van Halen, C., te Riele, H., \& Rommens, P. (1999). Product service systems, ecological and economic basics. Netherlands: Dutch Ministries of Environment (VROM) and Economic Affairs (EZ).

Harris, L. C., \& Reynolds, K. L. (2003). The consequences of dysfunctional customer behavior. Journal of Service Research, 6(2), 144-161.

Halme, M., Anttonen, M., Kusima, M., Kontoniemi, N., \& Heino, E. (2007). Business models for material efficiency services: Conceptualization and application. Ecological Economics, 63(1), 126-137.

Homburg, C., \& Stebel, P. (2009). Determinants of contract terms for professional services. Management Accounting Research, 20(2), 129-145.

Hypko, P., Tilebein, M., \& Gleich, R. (2010). Benefits and uncertainties of performancebased contracting in manufacturing industries: An agency theory perspective. Journal of Service Management, 21(4), 460-489.

Isaksson, O., Larsson, T. C., \& Rönnbäck, A.Ö. (2009). Development of product-service systems: Challenges and opportunities for the manufacturing firm. Journal of Engineering Design, 20(4), 329-348.

Jensen, M. C., \& Meckling, W. H. (1976). Theory of the firm: Managerial behavior, agency costs and ownership structure. Journal of Financial Economics, 3(4), 305-360.

Kindström, D. (2010). Towards a service-based business model-key aspects for future competitive advantage. European Management Journal, 28(6), 479-490.

Keow Cheng, S., \& Hon Kam, B. (2008). A conceptual framework for analysing risk in supply networks. Journal of Enterprise Information Management, 21(4), 345-360.

Kohtamäki, M., Partanen, J., Parida, V., \& Wincent, J. (2013). Non-linear relationship between industrial service offering and sales growth: The moderating role of network capabilities. Industrial Marketing Management, 42(8), 1374-1385.

Kowalkowski, C. (2010). What does a service-dominant logic really mean for manufacturing firms? CIRP Journal of Manufacturing Science and Technology, 3(4), 285-292.

Kuijken, B., Gemser, G., \& Wijnberg, N. M. (2017). Effective product-service systems: A value-based framework. Industrial Marketing Management, 60, 33-41.

Kuo, T. C. (2011). Simulation of purchase or rental decision-making based on product service system. The International Journal of Advanced Manufacturing Technology, 52(9-12), 1239-1249.

Lewis, M. A., \& Roehrich, J. K. (2009). Contracts, relationships and integration: Towards a model of the procurement of complex performance. International Journal of Procurement Management, 2(2), 125-142.

Logan, M. S. (2000). Using agency theory to design successful outsourcing relationships. The International Journal of Logistics Management, 11(2), 21-32.

Manzini, E., \& Vezzoli, C. (2003). A strategic design approach to develop sustainable product service systems: Examples taken from the 'environmentally friendly innovation' Italian prize. Journal of Cleaner Production, 11(8), 851-857.

Mascarenhas, B., \& Koza, M. P. (2008). Develop and nurture an international alliance capability. Thunderbird International Business Review, 50(2), 121-128.

Meier, H., Roy, R., \& Seliger, G. (2010). Industrial product-service systems-IPS2. CIRP Annals, 59(2), 607-627.

Nag, R., Corley, K. G., \& Gioia, D. A. (2007). The intersection of organizational identity, knowledge, and practice: Attempting strategic change via knowledge grafting. Academy of Management Journal, 50(4), 821-847.

Ng, I., \& Yip, N. (2009). Identifying risk and its impact on contracting through a benefit based-model framework in business to business contracting: Case of the defence industry. Proceedings of the 1st CIRP Industrial Product-Service Systems (IPS2) Conference (pp. 207-215). .

Ng, I. C., Ding, D. X., \& Yip, N. (2013). Outcome-based contracts as new business model: The role of partnership and value-driven relational assets. Industrial Marketing Management, 42(59), 730-743.

Nguyen, B., \& Simkin, L. (2013). The dark side of CRM: Advantaged and disadvantaged customers. Journal of Consumer Marketing, 30(1), 17-30.

Opresnik, D., \& Taisch, M. (2015). The value of big data in servitization. International Journal of Production Economics, 165, 174-184.

Plé, L., \& Chumpitaz Cáceres, R. (2010). Not always co-creation: Introducing interactional 
co-destruction of value in service-dominant logic. Journal of Services Marketing, 24(6), 430-437.

Parida, V., Sjödin, D. R., Lenka, S., \& Wincent, J. (2015). Developing global service innovation capabilities: How global manufacturers address the challenges of market heterogeneity. Research-Technology Management, 58(5), 35-44.

Poppo, L., \& Zenger, T. (2002). Do formal contracts and relational governance function as substitutes or complements? Strategic Management Journal, 23(8), 707-725.

Reim, W., Parida, V., \& Örtqvist, D. (2015). Product-service systems (PSS) business models and tactics-a systematic literature review. Journal of Cleaner Production, 97, 61-75.

Reim, W., Parida, V., \& Sjödin, D. R. (2016). Risk management for product-service system operation. International Journal of Operations \& Production Management, 36(6), 665-686.

Reim, W., Rönnberg Sjödin, D., \& Parida, V. (2014). Trust or control how to manage behavioural uncertainty for industrial product-service system provision? International CINet Conference.

Richter, A., Sadek, T., \& Steven, M. (2010). Flexibility in industrial product-service systems and use-oriented business models. CIRP Journal of Manufacturing Science and Technology, 3(2), 128-134.

Richter, A., \& Steven, M. (2009). On the relation between industrial product-service systems and business models. Operations Research Proceedings, 2008, 97-102.

Roy, R. (2000). Sustainable product-service systems. Futures, 32(3), 289-299.

Roy, R., \& Cheruvu, K. S. (2009). A competitive framework for industrial product-service systems. International Journal of Internet Manufacturing and Services, 2(1), 4-29.

Sakao, T., Rönnbäck, A.Ö., \& Sandström, G.Ö. (2013). Uncovering benefits and risks of integrated product service offerings-Using a case of technology encapsulation. Journal of Systems Science and Systems Engineering, 22(4), 421-439.

Sampson, S. E. (2000). Customer-supplier duality and bidirectional supply chains in service organizations. International Journal of Service Industry Management, 11(4), 348-364.

Schuh, G., Klotzbach, C., \& Gaus, F. (2008). Service provision as a sub-model of modern business models. Production Engineering, 2(1), 79-84.

Singh, J., \& Sirdeshmukh, D. (2000). Agency and trust mechanisms in consumer satisfaction and loyalty judgments. Journal of the Academy of Marketing Science, 28(1), 150-167.

Sjödin, D. R., Parida, V., \& Lindström, J. (2017). Barriers and conditions of open operation: A customer perspective on value co-creation for integrated product-service solutions. International Journal of Technology Marketing, 12(1), 90-111.

Sjödin, D. R., Parida, V., \& Wincent, J. (2016). Value co-creation process of integrated product-services: Effect of role ambiguities and relational coping strategies. Industrial Marketing Management, 56, 108-119.

Sousa, R., \& da Silveira, G. J. (2017). Capability antecedents and performance outcomes of servitization: Differences between basic and advanced services. International Journal of Operations \& Production Management, 37(4), 444-467.

Sundin, E., Öhrwall Rönnbäck, A., \& Sakao, T. (2010). From component to system solution supplier: Strategic warranty management as a key to efficient integrated product/service engineering. CIRP Journal of Manufacturing Science and Technology, 2(3), $183-191$.

Selviaridis, K., \& Norrman, A. (2014). Performance-based contracting in service supply chains: A service provider risk perspective. Supply Chain Management, 19(2), $153-172$.

Tukker, A. (2004). Eight types of product-service system: Eight ways to sustainability? Experiences from SusProNet. Business Strategy and the Environment, 13(4), 246-260.

Tukker, A. (2013). Product services for a resource-efficient and circular economy-A review. Journal of Cleaner Production, 97, 76-91.

Ulaga, W., \& Reinartz, W. J. (2011). Hybrid offerings: How manufacturing firms combine goods and services successfully. Journal of Marketing, 75(6), 5-23.

Vezzoli, C., Ceschin, F., Diehl, J. C., \& Kohtala, C. (2015). New design challenges to widely implement 'sustainable product-service systems'. Journal of Cleaner Production, 97, 1-12.

Visnjic, I., Wiengarten, F., \& Neely, A. (2016). Only the brave: Product innovation, service business model innovation, and their impact on performance. Journal of Product Innovation Management, 33(1), 36-52.

Xie, W., Jiang, Z., Zhao, Y., \& Shao, X. (2014). Contract design for cooperative product service system with information asymmetry. International Journal of Production Research, 52(6), 1658-1680. 